\title{
The Role of Hydrocarbon Fields Development in the Pollution of Water Resources of the Absheron Peninsula
}

\author{
Vagif Mammadov $^{1}$, Hadiya Khalilova ${ }^{2}$ \\ ${ }^{1}$ Institute of Geology and Geophysics of ANAS, AZ1143, Baku, Azerbaijan \\ ${ }^{2}$ Institute of Physics of ANAS, AZ1143, Baku, Azerbaijan
}

doi: https://doi.org/10.21467/abstracts.93.81

\begin{abstract}
A BS T RA C T
The Absheron peninsula is one of the most urbanized and ecologically critical (unfavorable) regions of the Republic of Azerbaijan. The relief of the peninsula was mainly formed in the alluvium period and includes gray-yellow sand, sandstone, limestone and clays, etc. with varying degrees of crinkles and salinity. Absolute altitudes are between 26 and 400 meters. The altitudes generally decline from the west to east and from center to the sea coast. The relief of the peninsula is characterised by arid-denudation and erosion processes, as well as ravines, hollows, eol and karst typical for the region's arid climate. Saline lakes and salt marshes are formed in the lower parts of the majority of valleys and ravines.

There are about 800 natural lakes in the country, 100 of which are located in the Absheron peninsula. One of the main features of this area is its richness with lakes. Lakes occupy $2.5 \%$ of the peninsula, which is about $0.35 \%$ for the republic. There are lakes of different origin and sizes, distinguished by hydro-chemical properties and natural resources. Some of these lakes have been subjected to anthropogenic loading on a different scale and directions from time to time. Intensive development of oil industry and the associated branches since the second half of the XIX century, the rapid growth in the agricultural sector in the midtwentieth and the urbanization of last decades have dramatically changed the quantity and quality of lakes in a number of lakes.

For example, at the beginning of the 20th century, daily 2-3 thousand $\mathrm{m}^{3}$ of waste water were released to the Boyuk Shore lake from nearby oil fields, and by 1970-80es this volume increased up to 30 thousand $\mathrm{m}^{3}$, that flooded the surrounding areas. Significant increase in water level has resulted in transferring a part of the untreated wastewater to the Mirzaladi lake consequently increasing the pollution of the latter. A huge amount of heavy metals, oil products, phenols, surfactants and other pollutants has accumulated in the surface waters and bottom sediments of these lakes. The amount of oil products in the water column often exceeds the maximum permissible concentration (MPC) by tens or sometimes hundreds times.

Chemical analyzes of bottom sediments have shown that almost all of the investigated lakes contain oil and petroleum products. Increased amounts of oil hydrocarbons were observed in the majority of these natural basins changing on the following order: Boyuk Shore - 270-400 g $/ \mathrm{kg}$ (in the middle and northern parts), Zabrat 1 -110-260 g / kg, Gala - 170-250 g / kg, Ramana - 200-330 g/kg, Girmyzy - 35-210 g / kg, Bulbula - 30-190 g / kg, Pirshagi - 90-150 g / kg, Masazir - 10-80 g/kg, Duzlu - 25-70 g / kg, and Hojahasan - 30$70 \mathrm{~g} / \mathrm{kg}$, etc.

A relatively small amount of oil products (about $1-30 \mathrm{~g} / \mathrm{kg}$ ) is observed in the bottom sediments of lakes located in the western part of the peninsula. With the pollution of lake basins, substances alien to limnogenesis began to accumulate in them, and this process with negative environmental, social, and economic consequences more progressively manifests itself in the enclosed lakes. The accelerated development of the oil and oil refining industries from the second half of the 19th century has radically changed the historically formed geochemical balance of the environment due to extraction of various (C) 2020 Copyright held by the author(s). Published by AIJR Publisher in "Abstracts of The Second Eurasian RISK-2020 Conference and Symposium” April 12- 19, 2020, Tbilisi, Georgia. Jointly organized by AMIR Technical Services LLC, Georgian Technical University, Institute of Geography (Kazakhstan) and Russian Institute of Petroleum Geology and Geophysics.

AijR DOI: $10.21467 /$ abstracts. 93
\end{abstract}


The Second Eurasian RISK-2020 Conference and Symposium

chemical elements, including heavy metals, from deep layers to the Earth's surface. Ultimately, a huge amount of microelements accumulates in the surface water basins. Being enriched with heavy metals the water masses, bottom sediments and the catchment areas of lakes become toxic over time, representing serious danger to all living organisms. Analysis of the research results have shown that, in the bottom sediments of most lakes, the contents of cadmium, zinc, lead and vanadium are 1.6-16.7, 1.1-6.4, 1.3-2.4, and 1.1-1.3 times higher than the Clark values of those in the sedimentary rocks, respectively.

The study of the pollution degree and telescoping mechanism of heavy metals in lake reservoirs with defining thier composition as well as the concentration, toxicity category and hazard class of each element is one of the urgent theoretical problems of modern geochemistry. The solution of these problems will determine the scale of technogenic discharges, ecological taxa of carcinogenic elements and their role in the environmental pollution.

Practice shows that the geochemical cycle of heavy metals under anthropogenic impact presents serious, sometimes unpredictable environmental consequences. Even partial pollution may result in rather tangible genetic restructuring of the entire system of the processes of mass and energy exchange in a lake type reservoir changing over time its entire typological appearance.

The study of trace elements of different genetic types in the Absheron water basins shows that their deposition occurs in accordance with the following two regularities: 1) the concentration of heavy metals is largely dependent on the chemical composition of the received water, enhancing their solubility; 2) the deposition of elements in different environment depends on their individual geochemical characteristics. Geochemical features and calculated data on the concentration of elements indicate that telescoping and deposition of elements are determined by the ionization potentials and the acid-base medium of the depositions.

In conclusion, it can be noted that:

- over the past century and a half, the pollution of the lakes of the Absheron peninsula has led to the fact that the anthropogenic factor in the lakes regime has become leading compared to the natural;

- the accumulation of uncharacteristic, alien chemicals in the aquatic environment including bottom sediments leads to oppression, and often the disappearance of the hydrobionts living there. Continuous pollution of the lakes and their watersheds manifests itself in wide-spectrum ecotoxicological anomalies; - precipitation of elements in the aquatic environment is selective, but not always subject to the general laws of sedimentation. In most cases, elements are deposited in neutral and alkaline environment. The bottom sediments are more susceptible to contamination than the upper parts of water basins;

- majority of the Absheron lakes have lost their natural regimes and resources (salt, therapeutic mud, etc.), and have become waste reservoirs that may cause various infectious diseases. Such lakes are also a potential source of fire hazard. 